\title{
Ultrastructure of the Infection of Sorghum bicolor by Colletotrichum sublineolum
}

\author{
P. S. Wharton, A. M. Julian, and R. J. O'Connell
}

First author: Department of Horticulture, A342 Plant and Soil Sciences Building, Michigan State University, East Lansing 48824; second author: Natural Resources Institute, University of Greenwich, Central Avenue, Chatham Maritime, Kent ME4 4TB, U.K.; and third author: IACR-Long Ashton Research Station, University of Bristol, Long Ashton, Bristol, BS41 9AF, U.K. Accepted for publication 25 October 2000.

\begin{abstract}
Wharton, P. S., Julian, A. M., and O'Connell, R. J. 2001. Ultrastructure of the infection of Sorghum bicolor by Colletotrichum sublineolum. Phytopathology 91:149-158.

Ultrastructural studies of the infection of susceptible and resistant cultivars of Sorghum bicolor by Colletotrichum sublineolum were conducted. Initial penetration events were the same on both susceptible and resistant cultivars. Germ tubes originating from germinated conidia formed globose, melanized appressoria, that penetrated host epidermal cells directly. Appressoria did not produce appressorial cones, but each penetration pore was surrounded by an annular wall thickening. Inward deformation of the cuticle and localized changes in staining properties of the host cell wall around the infection peg suggests that penetration involves both mechanical force and enzymic dissolution. In compatible

cells as an intracellular mycelium. Host cells initially survived penetration. The host plasma membrane invaginated around infection vesicles and primary hyphae and was appressed tightly to the fungal cell wall, with no detectable matrix layer at the interface. Necrotrophic secondary hyphae appeared after $66 \mathrm{~h}$ and ramified through host tissue both intercellularly and intracellularly, forming hypostromatic acervuli by $114 \mathrm{~h}$. Production of secondary hyphae was accompanied by the appearance of electron-opaque material within infected cells. This was thought to represent the host phytoalexin response. In incompatible interactions, infection vesicles and primary hyphae were formed in epidermal cells by $42 \mathrm{~h}$. However, they were encrusted with electron-opaque material and appeared dead. These observations are discussed in relation to the infection processes of other Colletotrichum spp. and the host phytoalexin response.
\end{abstract} interactions, penetration was followed by formation of biotrophic globular infection vesicles in epidermal cells. Filamentous primary hyphae developed from the vesicles and went on to colonize many other host
Additional keywords: anthracnose, Colletotrichum graminicola, hemibiotrophy, host-pathogen interactions, phytoalexins.
Sorghum anthracnose is one of the main constraints to grain production in most areas where sorghum is grown, namely the semi-arid tropics, south-eastern United States, and Latin America (19). The causal agent of anthracnose on cereals, including maize and sorghum, has been long regarded as Colletotrichum graminicola (5). However, analyses of rDNA sequences, DNA fingerprints, mating tests, and appressorial morphology have demonstrated clearly that isolates from maize and sorghum belong to distinct species $(23,29,31)$. Isolates from maize are now regarded as $C$. graminicola, whereas those from sorghum are designated $C$. sublineolum (30).

In a previous cytological study (32), we showed that $C$. sublineolum has a two-stage, hemibiotrophic infection process on sorghum, similar to that of $C$. lindemuthianum on bean (16). The initial biotrophic phase is associated with intracellular infection vesicles and primary hyphae, which colonize many host cells before giving rise to necrotrophic secondary hyphae. In incompatible interactions, host cells die soon after penetration by infection vesicles, and fungal development is restricted to a single epidermal cell (32). Accumulation of red-pigmented cytoplasmic inclusions containing 3-deoxyanthocyanidin phytoalexins (26), occurs

Corresponding author: R. J. O'Connell; E-mail address: richard.oconnel@bbsrc.ac.uk

* The $e$-Xtra logo stands for "electronic extra" and indicates the HTML abstract available on-line contains supplemental material not included in the print edition. On-line version contains a link to the sorghum anthracnose website.

Publication no. P-2000-1207-01R

(C) 2001 The American Phytopathological Society in both compatible and incompatible interactions, but this defense response is expressed much earlier in incompatible interactions $(9,32)$.

There have been no previous ultrastructural studies on the infection of sorghum by $C$. sublineolum, and very few such studies on cereal anthracnoses in general. The ultrastructure of the initial penetration of maize and oat leaves by $C$. graminicola has been described $(21,22)$, but postpenetration events were not considered. In this paper, we examine the infection of susceptible and resistant cultivars of sorghum by $C$. sublineolum with transmission and scanning electron microscopy. Our main aims were to document the ultrastructure of the biotrophic interface between intracellular primary hyphae and host cytoplasm, to determine the effects of infection on host cells, and to examine the ultrastructure of sorghum defense responses.

\section{MATERIALS AND METHODS}

Preparation of infected tissues. Isolates 117 and 74 of $C$. sublineolum P. Henn., Kabát \& Bubák, were maintained on quarterstrength potato dextrose agar (32). Conidial suspensions were prepared from 7-day-old cultures and the concentration was adjusted to $1 \times 10^{6}$ spores $\mathrm{ml}^{-1}$ with sterile deionized water. Three cultivars of Sorghum bicolor (L.) Moench, were used, namely cv. SC748-5 (resistant to both fungal isolates, obtained from Texas A\&M University), cv. KAD 332 (susceptible to both fungal isolates, obtained from W. de Millano, SADCC/ICRISAT, Matopos Research Station, Bulawayo, Zimbabwe), and cv. TAM 428 (susceptible to isolate 117 and resistant to 74, obtained from Texas A\&M University). All cultivars were grown in a controlled envi- 
ronment cabinet (32). Intact plants, rather than excised tissues, were used for inoculation, because wounding sometimes induces a phytoalexin defense response in sorghum (10). To facilitate accurate sampling of heavily infected tissues for transmission electron microscopy, droplets of spore suspension $(10 \mu \mathrm{l})$ were placed at 5 -mm intervals along the leaf sheaths of plants held horizontally inside Perspex boxes $\left(20 \times 12 \times 5 \mathrm{~cm}^{3}\right)$. The plants were initially grown for 18 days in pots before transplanting in boxes, where the roots and compost were held in a separate compartment from the stems and leaf sheaths, with the leaf laminae outside the box. Plants were grown for a further 3 days in an upright position to allow them to "acclimatize" to the boxes before inoculation. Before applying inoculation droplets, the wettability of the leaf sheath tissue was increased by brushing the surface gently with a camel hair paintbrush to disrupt epicuticular waxes. After inoculation, boxes were sealed inside polythene bags to maintain $100 \%$ humidity and incubated under the same conditions used to grow the plants (32).

Low temperature scanning electron microscopy. Observations were made using a Philips 505 scanning electron microscope interfaced with a Hexland cryo system (Oxford Instruments Ltd, Oxford, U.K.). Infected pieces of leaf sheath tissue (approximately $5 \times 5 \mathrm{~mm}^{2}$ ) were mounted, adaxial surface uppermost on a copper specimen holder, with a mixture of Tissue-Tek (Agar Scientific, Essex, England) and colloidal graphite. Samples were frozen by placing the specimen holder in contact with a copper block cooled to approximately $-170^{\circ} \mathrm{C}$ in the prechamber. The samples were transferred to the cold stage of the scanning electron microscope and examined at approximately $2.5 \mathrm{kV}$ for surface ice contamination. If present, ice was sublimed away by warming the specimen to between -60 and $-90^{\circ} \mathrm{C}$. The specimen holder was then returned to the prechamber, and samples were sputter-coated with approximately $12 \mathrm{~nm}$ of gold. After coating, samples were examined at an accelerating voltage of 9 to $10 \mathrm{kV}$ and a temperature below $-150^{\circ} \mathrm{C}$.

Transmission electron microscopy. At intervals after inoculation, pieces of leaf sheath tissue (approximately $1 \times 2 \mathrm{~mm}^{2}$ ) were excised from beneath inoculation sites and placed immediately in glutaraldehyde $(2.5 \%, \mathrm{vol} / \mathrm{vol})$ in $0.01 \mathrm{M}$ phosphate buffer (pH 6.8). Tissue was fixed for $3 \mathrm{~h}$, including 5-min vacuum-infiltration, washed in buffer $(3 \times 10 \mathrm{~min})$, and postfixed in osmium tetroxide $(1 \%, \mathrm{wt} / \mathrm{vol})$ in the same buffer for $3 \mathrm{~h}$. After washing in buffer $(3 \times 10 \mathrm{~min})$, tissue was dehydrated in a graded ethanol series, rinsed with propylene oxide, and embedded in Spurr's epoxy resin (TAAB Laboratories Equipment Ltd., Berkshire, U.K.) with flat embedding molds. Infection sites at precise stages of development were identified by light microscopy and prepared for sectioning according to the method of Zeyen and Bushnell (34). Ultrathin sections collected on Formvar-coated nickel slot grids (13) were stained with uranyl acetate and lead citrate and examined using a Hitachi 7100 transmission electron microscope (Hitachi Scientific Instruments Co., Tokyo).

\section{RESULTS}

Germination and penetration. The processes of germination, differentiation of appressoria, and penetration of sorghum leaf sheaths were the same in both compatible and incompatible interactions. Conidia of $C$. sublineolum typically germinated, producing germ tubes that formed globose, melanized appressoria close to conidia. Mature appressoria contained abundant mitochondria, lipid globules, glycogen granules, polyribosomes, multivesicular bodies, and vacuoles (Fig. 1A and B). Appressoria were surrounded by extracellular matrix material that extended outward over the leaf surface as a thin film, conforming to the irregular contours of the epicuticular wax (Fig. 1A). In many cases, the area of appressorial cell wall in contact with the host cuticle was relatively small (Fig. 1A). The appressorial wall consisted of two distinct layers: an outer, highly electron-opaque layer (approximately 60-nm thick) and an inner, moderately electron-opaque layer (approximately 90-nm thick) (Fig. 1A and B). A third electron-lucent layer was deposited at the base of the appressorium, between the inner wall layer and the plasma membrane, forming a thickened ring around the penetration pore (Fig. 1B). This layer was continuous with the cell wall of the infection peg, which emerged through the pore and penetrated the host cuticle and epidermal cell wall directly (Fig. 1B and C). Penetration by means of undifferentiated germ tubes (i.e., without appressoria) or penetration through stomata was never observed.

Sorghum epidermal cells had a very thin cuticular layer $(50 \mathrm{~nm})$ and a multilayered cell wall (Fig. 1B and C). The outer wall layers contained electron-opaque granules that had the typical ultrastructural appearance of silicon (4) and were concentrated particularly in a thin layer just below the cuticle (Fig. 1C). The putative silicon layer was most prominent in epidermal cells, located above leaf veins, but the thickness of the layer did not appear to affect the frequency with which host epidermal cells were penetrated. The infection peg was only 400 to $500 \mathrm{~nm}$ in diameter where it passed through the cell wall, and the wall of the infection peg (25- to 50-nm thick) was appressed closely to the host cell wall (Fig. 1B and C). At some penetration sites, the cuticle and putative silicon layer appeared to be forced down into the inner wall layers along the sides of the infection peg (Fig. 1B and C). Host wall microfibrils were severed cleanly, and there was a localized increase in electron opacity in the cell wall immediately adjoining the infection peg. Once the infection peg had penetrated the cell wall, a septum was usually produced at the junction with the intracellular hypha (Fig. 1C), or more rarely within the infection peg itself.

Varying amounts of host wall apposition material were deposited between the host plasma membrane and the epidermal cell wall at the site of penetration (Fig. 1B). These appositions were highly electron-opaque and varied in size from small, amorphous deposits to larger, layered structures. The latter type contained two distinct zones: a fibrillar layer abutting the host cell wall and a reticulate layer adjoining the host plasma membrane (Fig. 1B). In most cases, infection pegs were not restricted by these wall appositions, the remnants of which formed a collar around the neck of the infection vesicle (Fig. 2A). However, in approximately 1 to $5 \%$ of penetrations, the infection peg was completely encased by a papilla. Host cells containing papillae appeared dead, with a fragmented host plasma membrane and disorganized cytoplasm containing highly electron-opaque material (Fig. 1A and B). There were no obvious differences in the numbers of papillae formed in compatible and incompatible interactions.

Ultrastructure of compatible interactions. In compatible interactions (cv. KAD 332 challenged with both isolates 117 and 74, and cv. TAM 428 challenged with isolate 117), infection pegs had enlarged to form globose infection vesicles in the cell lumen by $42 \mathrm{~h}$ after inoculation (Fig. 2A). Infection vesicles were slightly smaller in diameter ( 7.5 to $9.5 \mu \mathrm{m}$ ) than the appressoria (8.5 to $10 \mu \mathrm{m})$. Filamentous primary hyphae had begun to grow out from some infection vesicles at $42 \mathrm{~h}$ (Fig. 2B). Primary hyphae grew entirely intracellularly and were observed only within epidermal and sclerenchyma cells, never in mesophyll cells. The host plasma membrane and thin peripheral layer of host cytoplasm became invaginated around both infection vesicles (Fig. 2A) and primary hyphae (Fig. 2B). Host nuclei often were associated closely with infection vesicles and primary hyphae (Fig. 2B). There was no visible matrix layer separating the host plasma membrane from the cell walls of infection vesicles and primary hyphae (Fig. 2B and $\mathrm{C}$ ), and in many cases the host plasma membrane appeared to be in direct contact with the fungal wall.

Where primary hyphae penetrated from cell to cell, they became greatly constricted (Fig. 3A), although the pores formed in the host cell wall were wider ( 0.5 to $1.0 \mu \mathrm{m}$ in diameter) than 

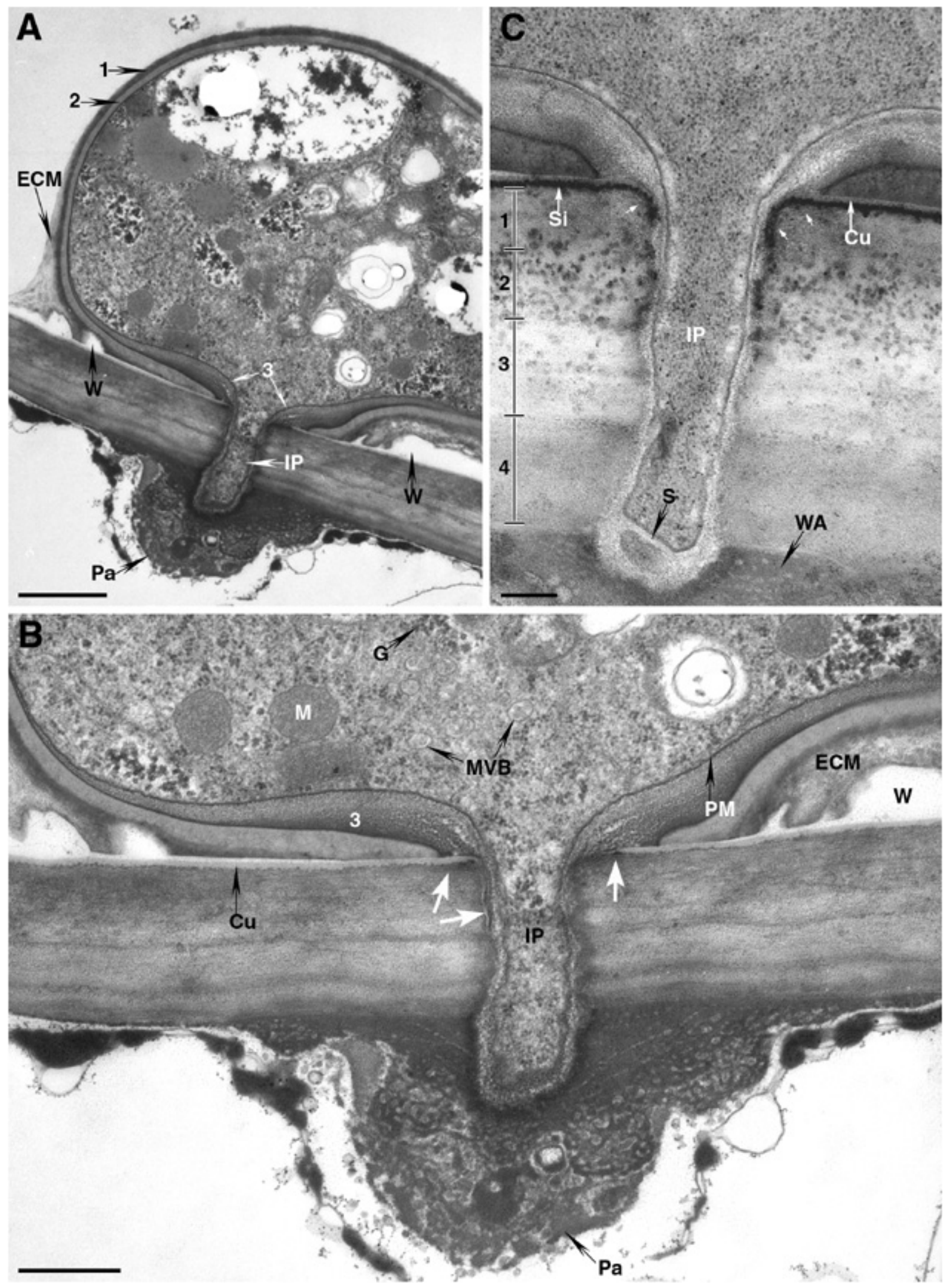

Fig. 1. Transmission electron micrographs showing penetration of sorghum epidermal cells by appressoria of Colletotrichum sublineolum $42 \mathrm{~h}$ after inoculation. A, Near-median section through an appressorium and infection peg (IP). The extracellular matrix (ECM) conforms to the contours of the leaf epicuticular wax layer (W). The appressorial wall consists of a highly electron-opaque outer layer (1) and a moderately electron-opaque inner one (2), with a third wall layer forming a thickened ring around the penetration pore (3). The infection peg has been encased by a host papilla $(\mathrm{Pa})$. Bar $=1 \mu \mathrm{m}$. B, Enlargement of the penetration site shown in A. The appressorial cytoplasm contains numerous mitochondria (M), glycogen granules $(\mathrm{G})$, polyribosomes and multivesicular bodies (MVB). Layer 3 of the appressorial wall is continuous with that of the infection peg (IP). The cuticle (Cu) appears to be pushed inward around the infection peg (arrows). The host papilla (Pa) is highly electron-opaque and multilayered. $\mathrm{PM}=$ plasma membrane; bar $=0.5 \mu \mathrm{m}$. $\mathbf{C}$, Near-median section through an infection peg (IP). The infection peg has penetrated the cuticle $(\mathrm{Cu})$ and epidermal cell wall, forming a septum (S) at the junction with the infection vesicle. Note the electron-opaque granules (Si) concentrated just beneath the cuticle and in the outer wall layers. The apparent silicon layer appears to have been deformed inward along with the cuticle and host wall microfibrils (arrows). Bar $=0.2 \mu \mathrm{m}$. 
those formed during the initial penetration of epidermal cells (cf. Fig. 1C and 3A). Primary hyphae also were able to penetrate the thickened, lignified walls of sclerenchyma cells (Fig. 3B and C). Wall penetration usually was accompanied by the formation of a septum, with associated Woronin bodies (Fig. 3A), but sometimes a septum was not produced (Fig. 3B). The hyphal wall was closely appressed to the host cell wall at points of penetration, and the host wall microfibrils appeared cleanly severed, with little evidence of deformation (Fig. 3A and B). Although wall appositions were not formed where hyphae passed from epidermal cell to epidermal cell, they sometimes occurred where hyphae passed from sclerenchyma cells into epidermal cells (Fig. 3B).

The cytoplasmic components of epidermal cells containing infection vesicles and primary hyphae initially retained normal ultra- tructure (Fig. 2A). However, after primary hyphae started to colonize adjacent cells (approximately $24 \mathrm{~h}$ after initial penetration), the previously infected cells began to degenerate. For example, discontinuities appeared in the plasma membrane, which retracted away from the host cell wall and hyphal walls (Fig. 3D). However, the cytoplasm of underlying uninfected mesophyll cells remained intact (Fig. 3D). By $66 \mathrm{~h}$, the cytoplasm of each infected cell was completely disrupted, with only membrane fragments remaining (Fig. 3E and F). The cell walls of primary hyphae within dead host cells (Fig. 3E) were thicker (125 to $200 \mathrm{~nm}$ ) than those in living cells (70 to $75 \mathrm{~nm}$ ) (cf. Figs. 2A and 3B). At $66 \mathrm{~h}$, many infected epidermal cells were collapsed and filled with a compacted layer of amorphous, moderately electron-opaque material (Fig. 4A).
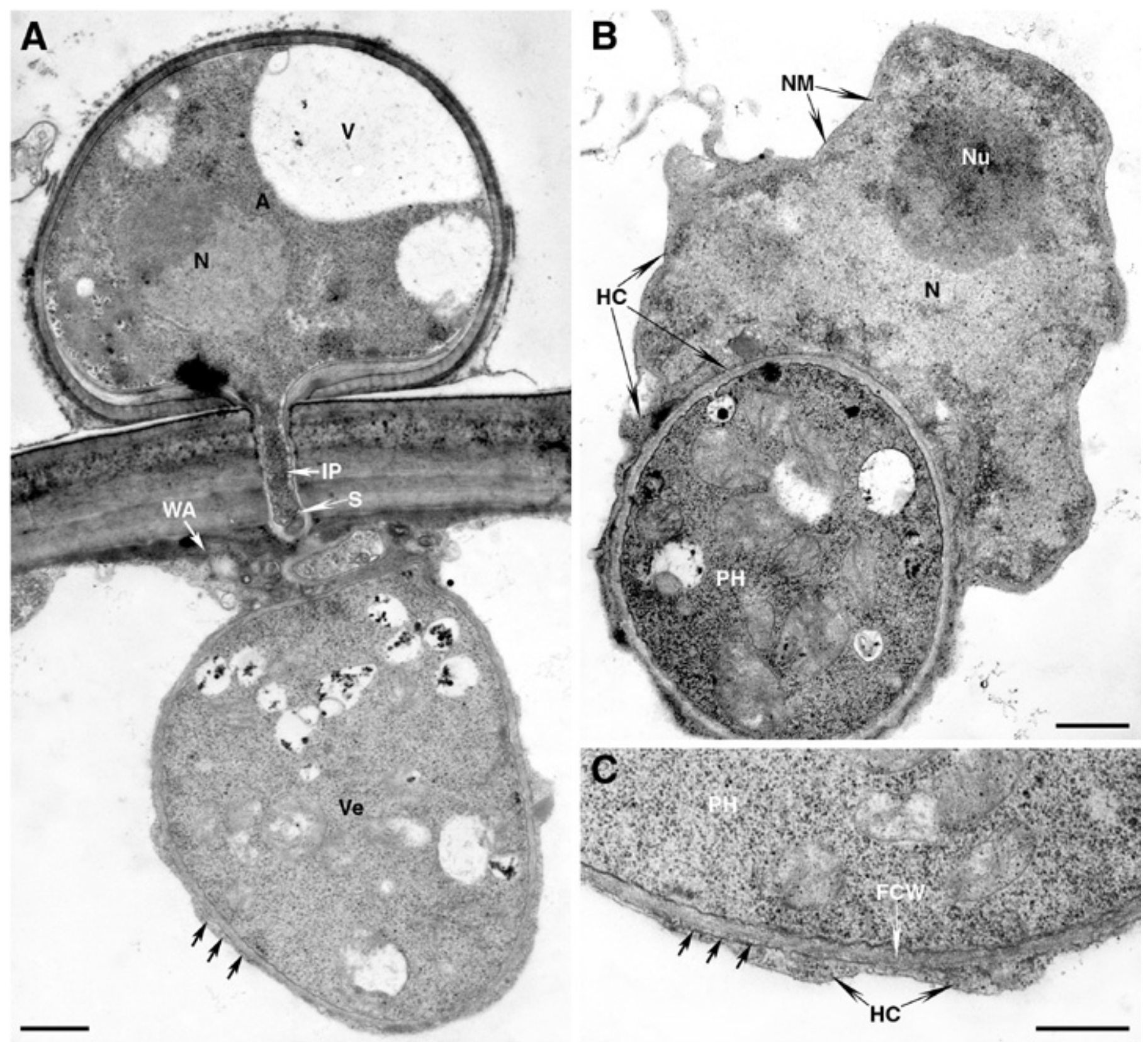

Fig. 2. Transmission electron micrographs showing the biotrophic development of intracellular hyphae of Colletotrichum sublineolum in sorghum epidermal cells $42 \mathrm{~h}$ after inoculation. A, An appressorium (A) and infection peg (IP) have given rise to an infection vesicle (Ve) inside a host epidermal cell. A septum (S) has formed at the junction between the infection peg and the infection vesicle. There is a thin layer of host cytoplasm invaginated around the vesicle (arrows). Host wall apposition material (WA) is present at the penetration site. $\mathrm{N}=$ nucleus; Bar $=1 \mu \mathrm{m}$. B, A primary hypha $(\mathrm{PH})$, partially enveloped by the host cell nucleus $(\mathrm{N})$. The host plasma membrane and a thin layer of cytoplasm $(\mathrm{HC})$ are invaginated around the primary hypha. Nu $=$ nucleolus; Bar $=0.5 \mu \mathrm{m}$. $\mathbf{C}$, High magnification micrograph, showing the interface between a primary hypha $(\mathrm{PH})$ and the host cell cytoplasm (HC). There is no significant matrix layer between the fungal cell wall (FCW) and the host plasma membrane (arrows), which appear to be in direct contact with each other. Bar $=0.5 \mu \mathrm{m}$. 

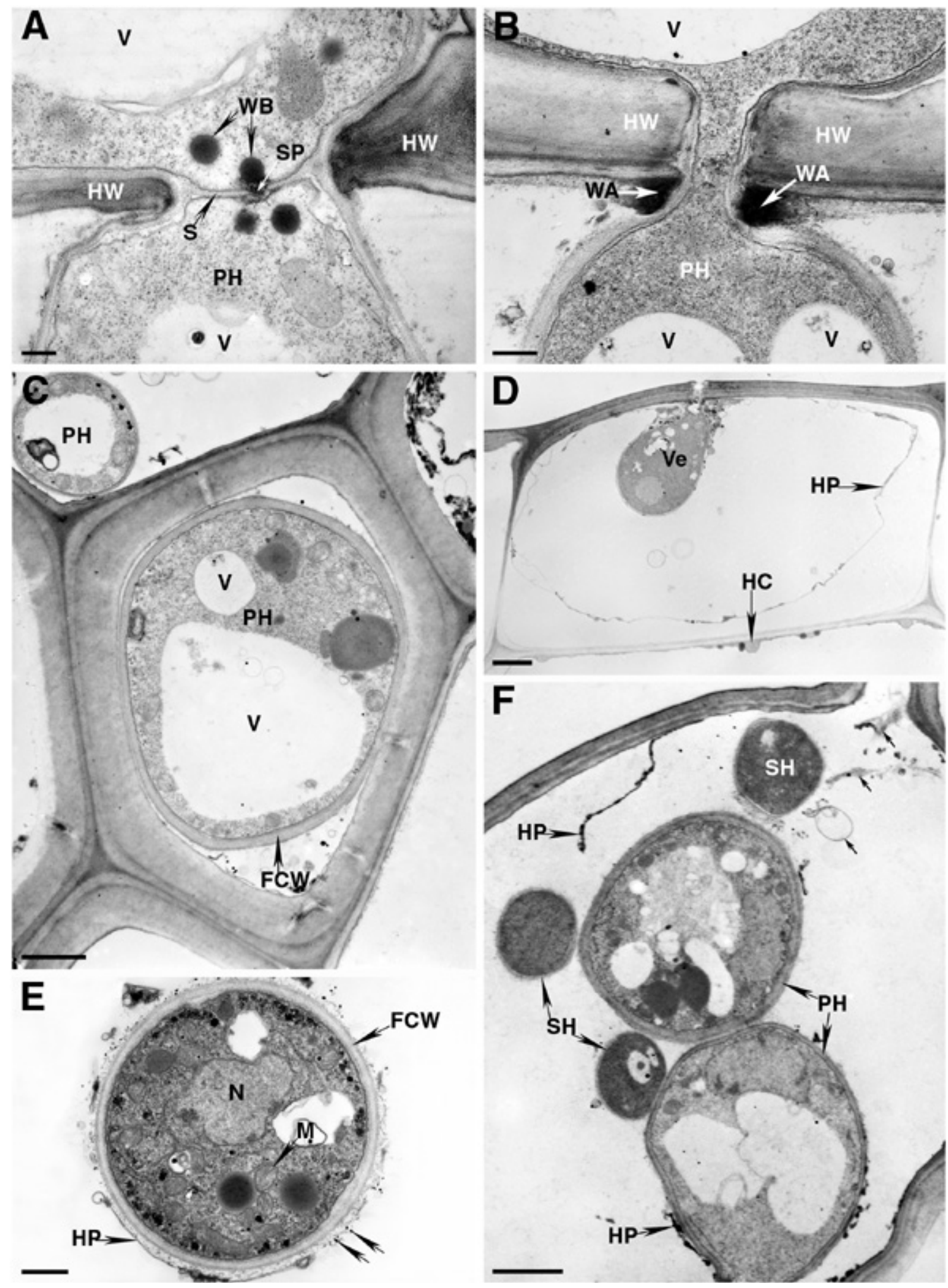

Fig. 3. Transmission electron micrographs showing colonization of sorghum tissues by primary and secondary hyphae of Colletotrichum sublineolum. A, Primary hypha $(\mathrm{PH})$ penetrating the cell wall between two epidermal cells $42 \mathrm{~h}$ after inoculation. The hypha has formed a septum (S) at the point of penetration. Note that the hyphal walls are appressed closely to the host cell wall at the penetration point and the host cell walls (HW) show little deformation. Woronin bodies (WB) are associated with the septal pore (SP). Bar $=0.2 \mu \mathrm{m}$. B, Primary hypha (PH) penetrating the secondary thickened cell wall (HW) between a sclerenchyma cell and an epidermal cell. Note the extreme constriction of the hypha as it passes through the wall and shows little sign of deformation. A layer of wall apposition material (WA) has been laid down in the epidermal cell. Bar $=0.4 \mu \mathrm{m}$. C, Primary hypha (PH) within a sclerenchyma cell $66 \mathrm{~h}$ after inoculation. The primary hypha is highly vacuolated $(\mathrm{V})$ and has a thick cell wall $(\mathrm{FCW})$. Bar $=1 \mu \mathrm{m}$. D, Epidermal cell containing an infection vesicle; $66 \mathrm{~h}$ after inoculation. The host plasma membrane (HP) has retracted away from the host cell wall and the host cytoplasm is disrupted. In contrast, the underlying mesophyll cell has intact cytoplasm (HC). Bar $=2 \mu \mathrm{m}$. E, Primary hypha in a dead host cell $66 \mathrm{~h}$ after inoculation. Note the thickness of the fungal cell wall (FCW) fragmented remnants of host plasma membrane (HP) and flocculent remnants of cytoplasm (arrows) around the hypha. $\mathrm{M}=$ mitochondria; Bar $=0.5 \mu \mathrm{m}$. $\mathbf{F}$, Infected epidermal cell containing large primary hyphae $(\mathrm{PH})$ together with smaller secondary hyphae $(\mathrm{SH}) 66 \mathrm{~h}$ after inoculation. The host cell cytoplasm is completely disrupted, with only fragments of the host plasma membrane (HP) and other cellular debris (arrows) remaining. Bar $=1 \mu \mathrm{m}$. 
Secondary hyphae first became visible in dead epidermal cells at $66 \mathrm{~h}$ (Fig. 3F). Secondary hyphae varied greatly in diameter ( 2 to $5 \mu \mathrm{m}$ ) and had much thinner walls (50- to 60-nm thick) than those of mature primary hyphae (Fig. 3F). Unlike primary hyphae, secondary hyphae often grew inside intercellular spaces (Fig. 4B), within host cell walls, or beneath the cuticle (Fig. 4C). The latter always remained intact, even after complete dissolution of the underlying cell wall. Secondary hyphae were never seen in contact with living host protoplasts.

By $90 \mathrm{~h}$, secondary hyphae had proliferated throughout the epidermal, mesophyll, and vascular tissues, and by $114 \mathrm{~h}$, numerous acervuli had been formed. Acervuli were initiated by the forma-
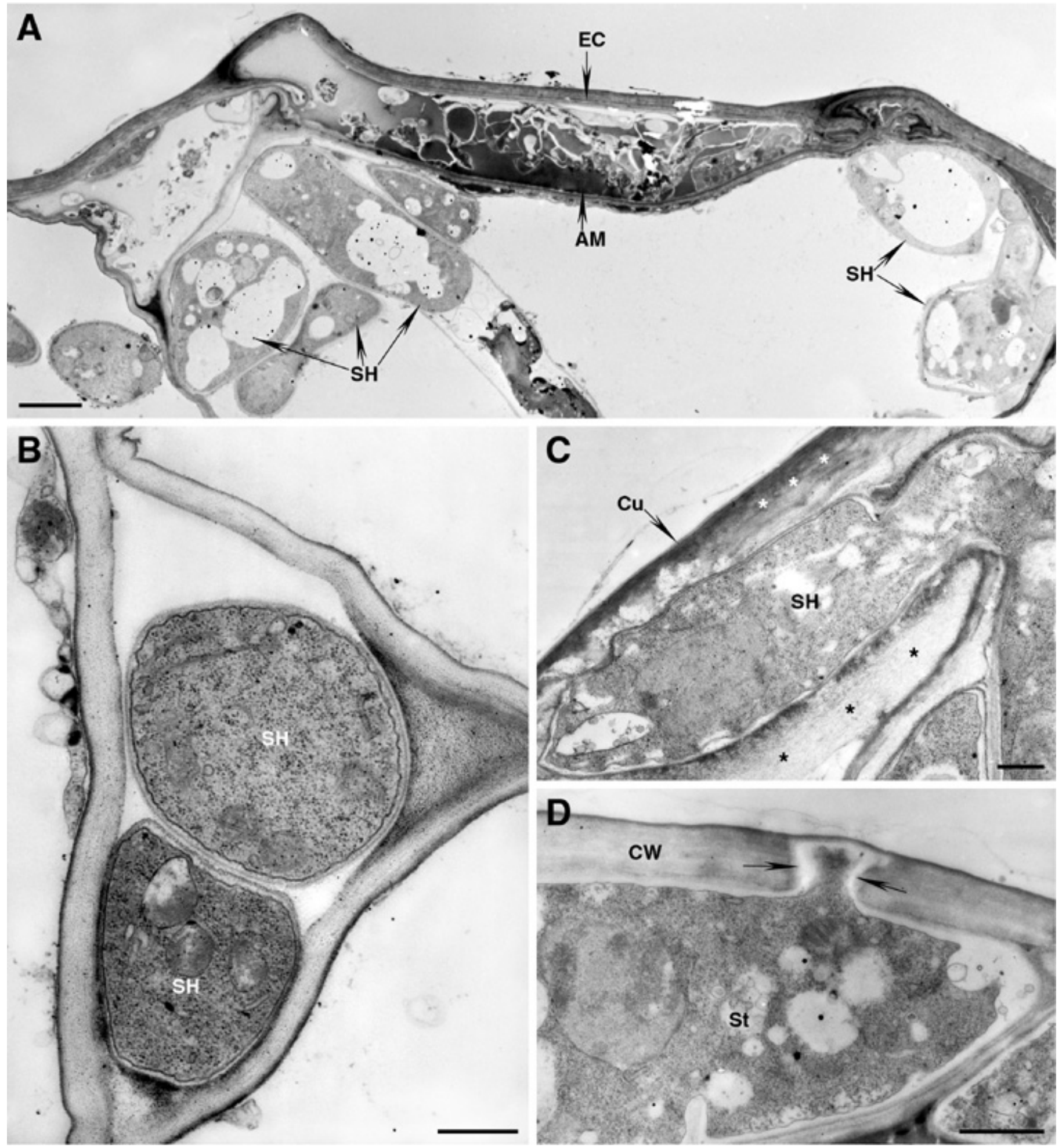

Fig. 4. Transmission electron micrographs showing necrotrophic colonization of sorghum tissues by Colletotrichum sublineolum. A, A collapsed infected epidermal cell (EC) containing a compacted layer of amorphous electron-opaque material (AM); $66 \mathrm{~h}$ after inoculation. The underl ying mesophyll cell contains secondary hyphae $(\mathrm{SH}) . \mathrm{Bar}=2.5 \mu \mathrm{m}$. B, Narrow secondary hyphae $(\mathrm{SH})$ growing within an intercellular space $90 \mathrm{~h}$ after inoculation. Bar $=0.5 \mu \mathrm{m}$. C, Subcuticular growth of secondary hyphae within the epidermal cell wall; $90 \mathrm{~h}$ after inoculation. Note the localized dissolution of the host cell walls around the secondary hyphae (*). Even though there is extensive dissolution of the epidermal cell wall, the host cuticle $(\mathrm{Cu})$ is still intact. Bar $=0.5 \mu \mathrm{m}$. D, High magnification micrograph showing an early stage in acervulus development $90 \mathrm{~h}$ after inoculation. A hyphal stroma (St) has given rise to a narrow penetration hypha (arrows) which has penetrated the epidermal cell wall $(\mathrm{CW})$ but not the cuticle. Bar $=1 \mu \mathrm{m}$. 
tion of a dense hyphal stroma in the epidermis. Outward penetration by the fungus involved localized dissolution of the epidermal cell wall, but not the cuticle, by narrow penetration hyphae (Fig. $4 \mathrm{D})$. These gave rise to conidiophores and setae between the cell wall and cuticle, and the subsequent expansion of these structures resulted in mechanical rupture of the cuticle. With scanning electron microscopy, acervuli appeared as masses of conidia through which long (70 to $100 \mu \mathrm{m})$ setae protruded (Fig. 5A and B). In cross section, the conidia were seen to arise from a mass of short conidiophores (Fig. 5C). The melanized setae were septate and had thick, electron-opaque cell walls. Each seta was usually devoid of cytoplasm, but intrahyphal hyphae were occasionally observed growing within them (Fig. 5C). Conidiophores and conidia were embedded in a fibrillar mucilage (Fig. 5C through E). Conidiophore cell walls consisted of a thin, electron-opaque outer layer and a thicker, moderately electron-opaque inner layer (Fig. 5D). Conidial cell walls contained two layers of similar thickness and electron-opacity separated by a thin layer of greater electronopacity (Fig. 5E). Cytoplasm in both conidiophores and conidia contained numerous lipid bodies, some of which were very large (Fig. 5C).

Ultrastructure of incompatible interactions. In incompatible interactions (cv. SC748-5 challenged with both isolates 117 and 74 and cv. TAM 428 challenged with isolate 74), infection pegs had penetrated epidermal cells to form infection vesicles and short primary hyphae by $42 \mathrm{~h}$, as in compatible interactions. However, all infected host cells appeared dead, with disrupted cytoplasm. In these cells, electron-opaque material was concentrated beneath appressoria around the site of initial penetration and was also associated with membranous debris (Fig. 6A and B). In cells in which papillae had formed, the papillae were heavily encrusted with electron-opaque material, which also accumulated within the infection peg (Fig. 6A). In all incompatible interactions at $42 \mathrm{~h}$, appressoria contained little or no cytoplasm and the residual membranous debris was encrusted with electron-opaque material (Fig. 6B). Similarly, the cytoplasm of infection vesicles and primary hyphae was heavily encrusted with electron-opaque material (Fig. 6A and B). Globules of amorphous material of moderate electron opacity accumulated in adjacent uninfected cells, especially along cell walls adjoining dead infected cells (Fig. 6C). The globules varied greatly in size and were not bounded by a membrane (Fig. 6D). By 66 h, all hyphae appeared dead and none had grown beyond the initially penetrated epidermal cell.

\section{DISCUSSION}

In the appressoria of some Colletotrichum spp., e.g., C. lagenarium, $C$. lindemuthianum, and $C$. trifolii, the basal penetration pore is surrounded by a funnel-shaped elaboration of the appressorial wall termed the appressorial cone $(7,11,14,33)$. However, in the present study, appressorial cones were never observed in $C$. sublineolum, and the penetration pore was instead surrounded by a thickened ring of wall material. Appressoria of $C$. graminicola, $C$. destructivum, and $C$. truncatum have an identical pore structure $(8,12,21,22)$, and a similar annular wall thickening, termed the pore wall overlay, surrounds the penetration pore of Magnaporthe grisea appressoria (2). It is unclear whether these differences in pore structure reflect different penetration mechanisms. Howard (6) suggests that both types of structure may form as the result of wall material accumulating around the pore when apical extension of the infection peg is restricted by the host cuticle or cell wall.

The inward deformation of the sorghum cuticle and outer wall layers around the infection peg of $C$. sublineolum suggests that initial penetration involves the exertion of mechanical force. However, penetration of the inner cell wall layers may involve highly localized enzymic dissolution, because the wall microfibrils appeared to be severed cleanly, and the staining properties of the cell wall immediately adjacent to infection pegs differed from that of the surrounding wall. Prominent deposits of material thought to be silicon in the periclinal walls of some epidermal cells did not appear to impede fungal penetration. Wall appositions of varying sizes were deposited at all penetration sites, but only a small number of infection pegs (1 to $5 \%$ ) were encased completely by papillae. This is likely to be a nonspecific response of sorghum epidermal cells to penetration, because there were no obvious differences in the numbers of papillae formed in compatible and incompatible interactions (data not shown). In Gramineae, papillae are a particularly important mechanism of resistance to penetration of epidermal cells by incompatible fungi (24).

Successful penetration was followed by the formation of globular infection vesicles and filamentous primary hyphae that went on to colonize many other host cells. In these respects, the initial infection process of $C$. sublineolum closely resembles that of $C$. lindemuthianum on bean (16). In contrast, the primary mycelia of other intracellular hemibiotrophs, such as $C$. destructivum and $C$. truncatum, are confined entirely to the first infected epidermal cell $(8,17)$. Using plasmolysis and vital staining, we have shown previously that sorghum cells initially survive penetration by infection vesicles and primary hyphae (32). The current study confirms the existence of a biotrophic phase, because the cytoplasm of penetrated host cells initially retained normal ultrastructure and the host plasma membrane invaginated around the growing infection vesicles and primary hyphae. However, the biotrophic phase only persisted for approximately $24 \mathrm{~h}$, after which the host plasma membrane and tonoplast lost structural integrity, correlated with a failure of penetrated cells to plasmolyse and accumulate vital stains (32). The biotrophic phases of $C$. destructivum and $C$. truncatum are similarly brief, being confined to the initially infected epidermal cell $(8,17)$, and although biotrophy persists longer (72 to $96 \mathrm{~h}$ ) in the $C$. lindemuthianum-bean interaction, only recently penetrated host cells at the advancing margin of the primary mycelium are alive, whereas previously infected cells are dead or senescent (16).

During the biotrophic phase of $C$. lindemuthianum, infection vesicles and primary hyphae are surrounded by an interfacial matrix that separates the fungal cell wall from the invaginated host plasma membrane (15). Recently, a fungal proline-rich glycoprotein, $\mathrm{CIH} 1$, was identified within this matrix and shown to be expressed uniquely at the biotrophic interface with bean protoplasts $(18,20)$. Similar interfacial matrices also surround the haustoria and intracellular hyphae of most biotrophic fungi and are likely to have important roles in the maintenance of biotrophy and avoidance or suppression of host defense responses $(3,25)$. However, in the current study, no matrix layer was detected around the intracellular hyphae of $C$. sublineolum, and instead the host plasma membrane appeared to be in direct contact with the fungal cell wall. The absence of a specialized interface between $C$. sublineolum and sorghum cells could explain the limited duration of biotrophy in this interaction.

The necrotrophic phase of infection was associated with the appearance of narrow secondary hyphae at $66 \mathrm{~h}$. Whereas primary hyphae were confined largely to epidermal and sclerenchyma cells, secondary hyphae ramified throughout the leaf sheath, including the underlying mesophyll and vascular tissue. Unlike the entirely intracellular primary mycelium, secondary hyphae grew both inside and between host cells, inside host cell walls, and beneath the cuticle. Host cell walls in the immediate vicinity of secondary hyphae were degraded and swollen, suggesting that wall-degrading enzymes are secreted at this stage. However, wall dissolution was more restricted than in the necrotrophic phase of C. lindemuthianum on bean, where host walls are degraded up to $200 \mu \mathrm{m}$ ahead of infection (16). Host cell death is also more restricted in the necrotrophic phase of the C. sublineolum-sorghum interaction (32).

The production of acervuli involved fungal egress from the host tissue by means of localized enzymic penetration of the epidermal 

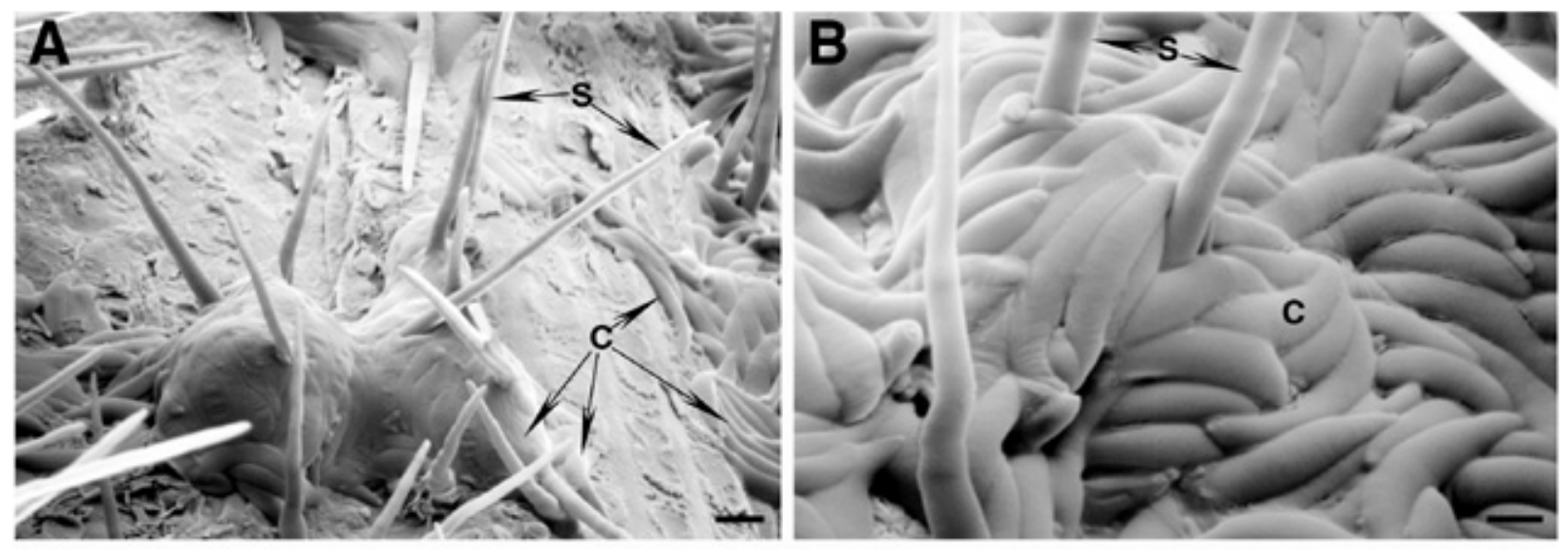

C
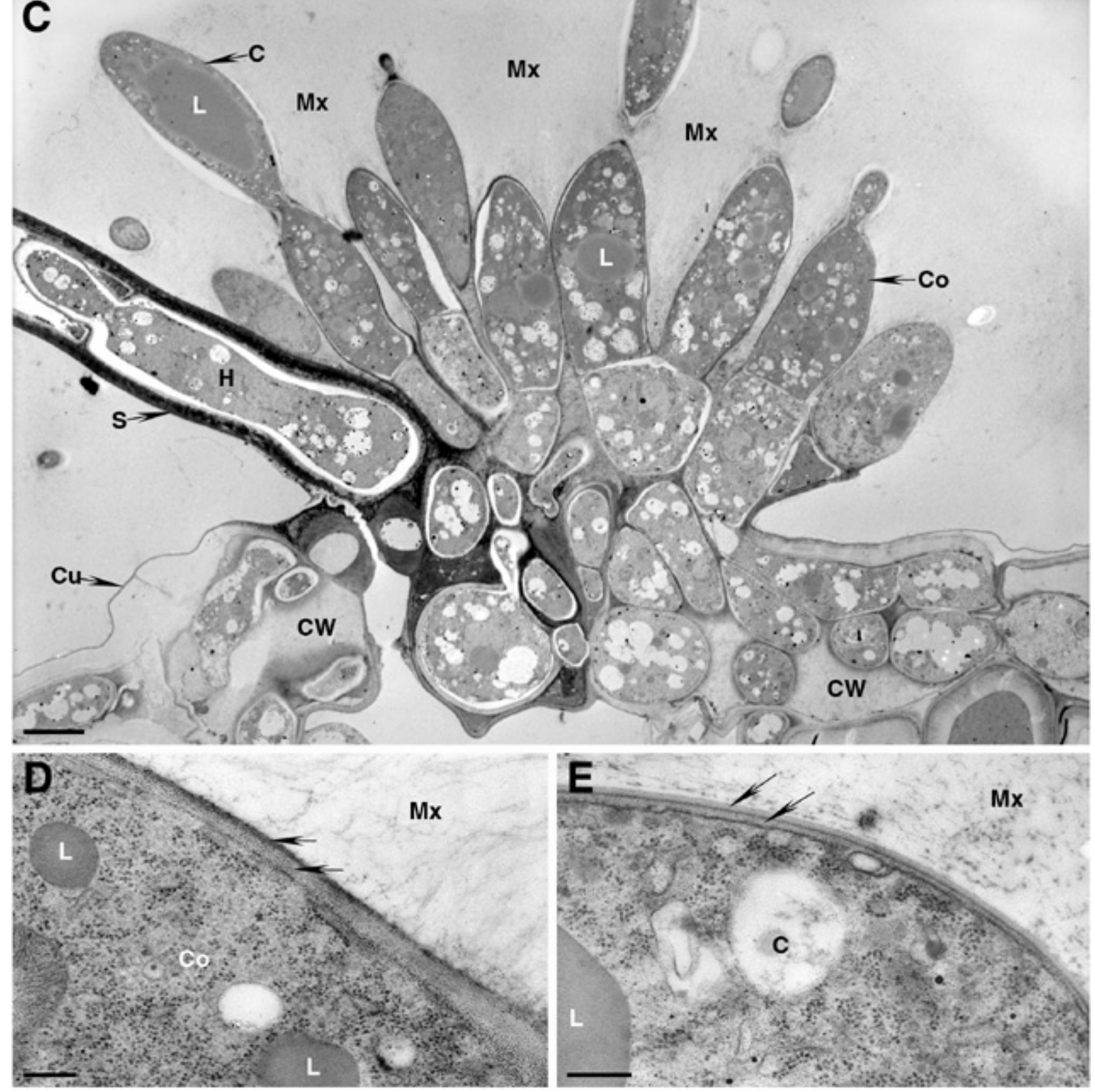

Fig. 5. Electron micrographs showing the formation of acervuli on sorghum leaf sheaths by Colletotrichum sublineolum $114 \mathrm{~h}$ after inoculation. A, Scanning electron micrograph of an acervulus. Setae $(\mathrm{S})$ can be seen protruding through the extracellular matrix in which the conidia $(\mathrm{C})$ are embedded. Bar $=10 \mu \mathrm{m}$. B, High magnification scanning electron micrograph of the surface of an acervulus, showing setae (S) protruding through the dense mass of conidia $(\mathrm{C})$. Bar $=5 \mu \mathrm{m}$. C, Transmission electron micrograph of an acervulus. The acervulus contains a thick-walled seta (S), conidiophores (Co) and conidia (C) which are all embedded in a fibrillar matrix $(\mathrm{Mx})$. Note the intrahyphal hypha $(\mathrm{H})$ in the seta and the large lipid bodies $(\mathrm{L})$ within the conidia and conidiophores. Note also that even though there is extensive dissolution of the epidermal cell wall $(\mathrm{CW})$, the host cuticle $(\mathrm{Cu})$ is still intact. Bar $=2.5 \mu \mathrm{m}$. D and E, Transmission electron micrographs showing $\mathbf{D}$, parts of a conidiophore and $\mathbf{E}$, a conidium. The conidiophore (Co) and conidium (C) are surrounded by a fibrillar matrix (Mx) and contain numerous lipid bodies (L). D, The cell wall of the conidiophore is composed of a highly electron-opaque outer layer and a moderately electronopaque inner layer, whereas $\mathbf{E}$, the cell wall of the conidium is composed of two moderately electron-opaque layers (arrows). Bars $=0.25 \mu \mathrm{m}$. 
cell wall by narrow hyphae. The cuticle appeared to be ruptured mechanically, following the expansion of conidia, conidiophores, and setae between the cell wall and cuticle. This type of acervulus development is termed hypostromatic and has been reported in all Colletotrichum spp. infecting graminaceous hosts (28). In contrast, most other Colletotrichum spp. produce pulvinate acervuli, in which the epidermal wall and cuticle are ruptured simultaneously by the expanding mass of sporogenous tissue $(1,28)$. It is unclear whether the hypostromatic development of acervuli on grasses results from a difference in pathogen behavior or from the unique structure or mechanical properties of leaf tissues in Gramineae.

In incompatible interactions between $C$. sublineolum and sorghum, infection vesicles and short primary hyphae are formed but their growth is restricted to a single epidermal cell, probably as a result of phytoalexin production (32). Five different 3-deoxyanthocyanidin phytoalexins have been identified in sorghum, and the red pigmentation of these compounds has allowed the time of their accumulation during resistant responses to $C$. sublineolum to be monitored by light microscopy $(9,27,32)$. Colorless vesicle-like inclusions first appear in the cytoplasm of infected cells $24 \mathrm{~h}$ after inoculation and migrate toward sites of penetration. These vesi- cles gradually enlarge and coalesce, becoming progressively more red-pigmented. By $42 \mathrm{~h}$ after inoculation they have burst and released the red pigments, which become distributed throughout the host epidermal and fungal cells $(27,32)$. The highly electronopaque material seen encrusting dead host and fungal cells at $42 \mathrm{~h}$ after inoculation (Fig. 6A and B) is likely to represent the phytoalexins, because it has the same distribution as the red pigments. Pigmented vesicles also accumulate in surrounding uninfected cells along the cell wall adjoining the penetrated cell (27). In this study, we observed globules containing moderately electronopaque material at the same location within uninfected cells (Fig. 6C), and we interpret these to be the ultrastructural equivalent of the red-pigmented vesicles.

In compatible interactions at $66 \mathrm{~h}$, collapsed epidermal cells were also packed with a moderately electron-opaque material (Fig. 4A), which probably corresponds to the orange-red pigment seen in dead host cells at this time by light microscopy (32). Although 3-deoxyanthocyanidin phytoalexins accumulate during the necrotrophic phase of the compatible interaction, they do not restrict fungal growth. Recent biochemical data indicate this may be because phytoalexins accumulate more slowly and reach lower concentrations in susceptible sorghum cultivars than in resistant

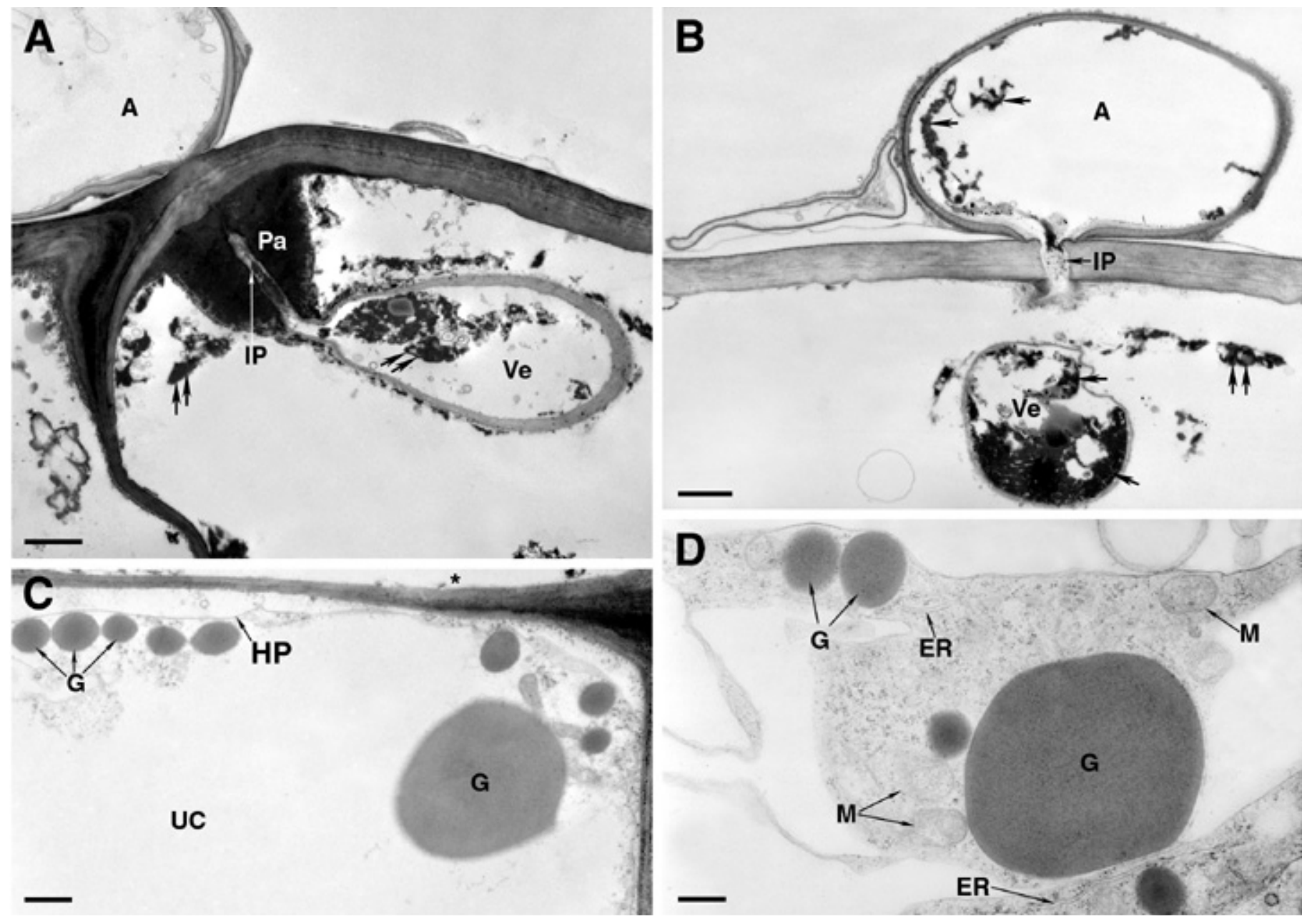

Fig. 6. Transmission electron micrographs showing resistant responses of sorghum tissues to incompatible isolates of Colletotrichum sublineolum at $42 \mathrm{~h}$ after inoculation. A, Section through an appressorium (A), papilla (Pa), and infection vesicle (Ve) within an epidermal cell of cv. SC748-5 inoculated with isolate 117. The infection peg (IP) was able to penetrate the large papilla deposited on the inner surface of the cell wall. Both the infection vesicle and host cell are devoid of cytoplasm, containing only membranous debris encrusted with highly electron-opaque material (arrows). The papilla is also heavily encrusted with electron-opaque material. Bar $=1 \mu \mathrm{m}$. B, Near-median section through an appressorium (A), infection peg (IP), and infection vesicle (Ve) in an epidermal cell of cv. TAM 428 inoculated with isolate 74. Membranous debris in the appressorium, infection vesicle, and host cell is encrusted with highly electron-opaque material (arrows). Bar $=1 \mu \mathrm{m}$. C and D, Cv. TAM 428 inoculated with isolate 74. Bars $=0.5 \mu \mathrm{m}$. C, Accumulation of globules of moderately electron-opaque material (G) along the cell wall, between an uninfected epidermal cell (UC) and an adjacent infected cell (asterisk). The host plasma membrane (HP) is retracted from the cell wall and the host tonoplast is disrupted. D, Globules of moderately electron-opaque material (G) within an uninfected cell. The globules are not bound by a membrane. $\mathrm{ER}=$ endoplasmic reticulum; $\mathrm{M}=$ mitochondria . 
cultivars (9). There is also evidence that the compounds accumulating in susceptible cultivars are less fungitoxic (9).

The results of this study suggest that the events leading to compatibility or incompatibility in the sorghum-C. sublineolum pathosystem occur soon after initial penetration of epidermal cells. In compatible interactions, the infected cells remain alive after invasion with the formation of a biotrophic interaction. In incompatible interactions, rapid accumulation of pigmented cytoplasmic inclusions containing phytoalexins leads to the death of infected cells and disruption of the fungal cytoplasm, so preventing further hyphal development (32). In compatible interactions, the proliferation of primary hyphae into surrounding cells was only observed after the establishment of a biotrophic interaction in the first colonized cell. This initial biotrophic phase may allow the fungus to become established within sufficient tissue to lessen the inhibitory effects of defense compounds. However, the mechanisms of recognition that determine compatibility or incompatibility between host and pathogen are currently unclear and require further investigation.

\section{ACKNOWLEDGMENTS}

This document is an output from a project through the Crop Protection Research Programme of the U.K. Department for International Development (DFID) for the benefit of developing countries. The views expressed are not necessarily those of DFID Project R5349 Crop Protection Research Program. IACR-Long Ashton received grant support from the Biotechnology and Biological Sciences Research Council of the United Kingdom. The work was performed under authority given by MAFF license PHF870B/405/33. We thank R. J. Pring for help with scanning electron microscopy and J. A. Bailey for critical reading of the manuscript.

\section{LITERATURE CITED}

1. Bailey, J. A., O'Connell, R. J., Pring, R. J., and Nash, C. 1992. Infection strategies of Colletotrichum species. Pages 88-120 in: Colletotrichum: Biology, Pathology, and Control. J. A. Bailey and M. J. Jeger, eds. CAB International, Wallingford, U.K.

2. Bourett, T. M., and Howard, R. J. 1990. In vitro development of penetration structures in the rice blast fungus Magnaporthe grisea. Can. J. Bot. 68:329-342.

3. Gay, J. L. 1984. Mechanisms of biotrophy in fungal pathogens. Pages 49-59 in: Plant Diseases: Infection, Damage, and Loss. R. K. S. Wood and J. Jellis, eds. Blackwell Scientific Publications, Oxford.

4. Heath, M. C. 1979. Partial characterization of the electron-opaque deposits formed in the non-host plant, French bean, after cowpea rust infection. Physiol. Plant Pathol. 15:141-148.

5. Holliday, P. 1980. Fungus Diseases of Tropical Crops. Cambridge University Press, Cambridge.

6. Howard, R. J. 1997. Breaching the outer barriers-cuticle and cell wall penetration. Pages 43-60 in: The Mycota, vol. 5, Part A, Plant Relationships. G. C. Carroll and P. Tudzynski, eds. Springer-Verlag, Berlin.

7. Landes, M., and Hoffman, G. M. 1979. Ultrahistological investigations of the interactions in compatible and incompatible systems of Phaseolus vulgaris and Colletotrichum lindemuthianum. Phytopathol. Z. 96:330-351.

8. Latunde-Dada, A. O., O'Connell, R. J., Nash, C., Pring, R. J., Lucas, J. A., and Bailey, J. A. 1996. Infection process and identity of the hemibiotrophic anthracnose fungus (Colletotrichum destructivum) from cowpea (Vigna unguiculata). Mycol. Res. 100:1133-1141.

9. Lo, S.-C. C., De Verdier, K., and Nicholson, R. L. 1999. Accumulation of 3-deoxyanthocyanidin phytoalexins and resistance to Colletotrichum sublineolum in sorghum. Physiol. Mol. Plant Pathol. 55:263-273.

10. Lopez, A. M. Q., and Pascholati, S. F. 1992. Accumulation of a complex of pigments in sorghum mesocotyls in response to wounding. J. Phytopathol. 135:63-70.

11. Mercer, P. C., Wood, R. K. S., and Greenwood, A. D. 1971. Initial infec- tion of Phaseolus vulgaris by Colletotrichum lindemuthianum. Pages 381-389 in: Ecology of Leaf Surface Micro-Organisms. T. F. Preece and C. H. Dickinson, eds. Academic Press, London.

12. Mims, C. W. 1991. Using electron microscopy to study plant pathogenic fungi. Mycologia 83:1-19.

13. Moran, D. T., and Rowley, J. C. 1987. Correlative Microscopy in Biology: Instrumentation and Methods. Academic Press, New York.

14. Mould, M. J. R., Boland, G. J., and Robb, J. 1991. Ultrastructure of the Colletotrichum trifolii - Medicago sativa pathosystem: Pre-penetration events. Physiol. Mol. Plant Pathol. 38:179-194.

15. O'Connell, R. J. 1987. Absence of a specialized interface between intracellular hyphae of Colletotrichum lindemuthianum and cells of Phaseolus vulgaris. New Phytol. 107:725-734.

16. O'Connell, R. J., Bailey, J. A., and Richmond, D. V. 1985. Cytology and physiology of infection of Phaseolus vulgaris by Colletotrichum lindemuthianum. Physiol. Plant Pathol. 27:75-98.

17. O'Connell, R. J., Uronu, A. B., Waksman, G., Nash, C., Keon, J. P. R., and Bailey, J. A. 1993. Hemibiotrophic infection of Pisum sativum by Colletotrichum truncatum. Plant Pathol. 42:774-783.

18. Pain, N. A., O’Connell, R. J., Mendgen, K., and Green, J. R. 1994. Identification of glycoproteins specific to biotrophic intracellular hyphae formed in the Colletotrichum lindemuthianum-bean interaction. New Phytol. 127:233-242.

19. Pastor-Corrales, M. A., and Frederiksen, R. A. 1980. Sorghum anthracnose. Pages 289-294 in: Sorghum Diseases: A World Review. Proc. Int. Workshop Sorghum Dis. R. J. Williams, R. A. Frederiksen, and L. K. Mughogho, eds. International Crops Research Institute for the Semi-Arid Tropics, Patancheru, India.

20. Perfect, S. E., O'Connell, R. J., Green, E. F., Doering-Saad, C., and Green, J. R. 1998. Expression cloning of a fungal proline-rich glycoprotein specific to the biotrophic interface formed in the Colletotrichumbean interaction. Plant J. 15:273-279.

21. Politis, D. J. 1976. Ultrastructure of penetration by Colletotrichum graminicola of highly resistant oat leaves. Physiol. Plant Pathol. 8:117-122.

22. Politis, D. J., and Wheeler, H. 1973. Ultrastructural study of penetration of maize leaves by Colletotrichum graminicola. Physiol. Plant Pathol. 3:465-471.

23. Sherriff, C., Whelan, M. J., Arnold, G. M., and Bailey, J. A. 1995. rDNA sequence analysis confirms the distinction between Colletotrichum graminicola and C. sublineolum. Mycol. Res. 99:475-478.

24. Sherwood, R. T., and Vance, C. P. 1980. Resistance to fungal penetration in Gramineae. Phytopathology 70:273-279.

25. Siegrist, J., and Kauss, H. 1990. Chitin deacetylation in cucumber leaves infected by Colletotrichum lagenarium. Physiol. Mol. Plant Pathol. 36:267-275.

26. Snyder, B. A., Leite, B., Hipskind, J., Butler, L. G., and Nicholson, R. L. 1991. Accumulation of sorghum phytoalexins induced by Colletotrichum graminicola at the infection site. Physiol. Mol. Plant Pathol. 39:463-470.

27. Snyder, B. A., and Nicholson, R. L. 1990. Synthesis of phytoalexins in sorghum as a site specific response to fungal ingress. Science 248:1637-1639.

28. Sutton, B. C. 1966. Development of fructifications in Colletotrichum graminicola (Ces.) Wils. and related species. Can. J. Bot. 44:887-897.

29. Sutton, B. C. 1968. The appressoria of Colletotrichum graminicola and C. falcatum. Can. J. Bot. 46:873-876.

30. Sutton, B. C. 1980. The Coelomycetes: Fungi Imperfecti with Pycnidia, Acervuli, and Stromata. Commonw. Mycol. Inst., Kew, London.

31. Vaillancourt, L. J., and Hanau, R. M. 1992. Genetic and morphological comparisons of Glomerella (Colletotrichum) isolates from maize and from sorghum. Exp. Mycol. 16:219-229.

32. Wharton, P. S., and Julian, A. M. 1996. A cytological study of compatible and incompatible interactions between Sorghum bicolor and Colletotrichum sublineolum. New Phytol. 134:25-34.

33. Xuei, X. L., Jarlfors, U., and Kuc, J. 1988. Ultrastructural changes associated with induced systemic resistance of cucumber to disease: Host response and development of Colletotrichum lagenarium. Can. J. Bot. 66:1028-1038.

34. Zeyen, R. J., and Bushnell, W. B. 1981. An in block, light microscope viewing procedure for botanical materials in plastic embedments: With emphasis on location and selection of the host cell-microbe encounter sites. Can. J. Bot. 59:397-402. 